\title{
Design of Ultra Wide Band Omni Mono-Cone Antenna
}

\author{
Shuo Cui ${ }^{1, a}$, Sen Wang ${ }^{2, b}$ and $\mathrm{Hao} \mathrm{Li}^{3, \mathrm{c}}$ \\ ${ }^{1}$ No.2006, Xiyuan Ave, West Hi-Tech Zone, Chengdu,.China \\ ${ }^{2}$ No.1, Nan Da Hong Men Road, Fengtai District, Beijing, China \\ ${ }^{3}$ No. 1, Nan Da Hong Men Road, Fengtai District, Beijing, China \\ accshuofred@foxmail.com, b15908109077@163.com,c952077096@qq.com
}

Keywords: ultra-wideband; omnidirectional; Mono-cone; miniaturization

Abstract. This paper puts forward and designs an ultra-wideband omnidirectional mono-cone antennas used for reverberation chamber to send and receive microwave. The ground plane uses the bending design, and the cone is designed to step in order to reduce the size and weight. It is easy to take along and install. The working band of the antenna is $0.8-6 \mathrm{GHz}$. Through HFSS simulation prove that the VSWR within the work frequency is less than 2. The H-plane pattern has fine out-of-roundness which less than $1 \mathrm{~dB}$. The E-pattern is similar to an apple and the gain is greater than $1 \mathrm{dBi}$ in all band. The antenna main characteristic is ultra-wideband, miniaturization and omnidirectional radiation. The antenna has good characteristics of impedance and pattern in the wide band.

\section{Introduction}

As a kind of wireless communication technology, Ultra-wideband (UWB) become one of the most competitive and development prospect technologies with its big communication capacity in high frequency, good security, and low average power density. The first double cone antenna with broadband characteristics was made by Lodge in 1898, It can be regard as a uniform gradient line which excite TEM mode. It's input impedance has wide band character. After that, Carter improved double cone antenna and single cone antenna (1939). Schelkunoff made spherical antenna (1941), and Kan-doian made discone antenna (1945), etc. Most antenna's physical size is larger, so the size of floor needs to be controlled within a certain range to get a better voltage standing wave ratio. Today, as an important part of wireless communication system, Ultra-wideband antenna has higher requirements in terms of carrying and installation.[1,2,3]

\section{Theory on Design}

The conical antenna is a kind of typical wideband antenna upload travelling wave in infinite metal plane. Theoretically, it has infinite wide working bandwidth which means that it is independent of the frequency. The finite length mono-cone antenna in the infinite metal plane is shown in Fig.1.

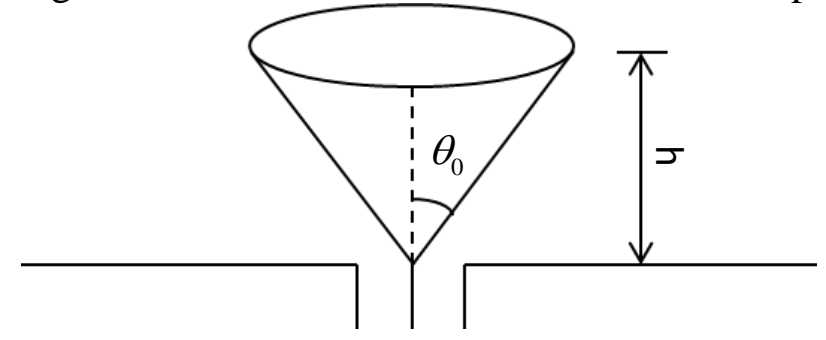

Fig. 1 the mono-cone antennas in the infinite metal plane

The input impedance on mono-cone antenna feed is[4,5]:

$$
Z_{\text {in }}=Z_{0} \frac{1-\beta / \alpha}{1+\beta / \alpha}
$$

$\beta / \alpha$ is the amplitude ratio of reflected wave in antenna area and the extroversion transverse electromagnetic wave (TEM) . $Z_{0}$ is characteristic impedance of the mono-cone antenna, 


$$
Z_{0}=60 \operatorname{In}\left(\cos \frac{\theta_{0}}{2}\right)
$$

$\theta_{0}$ is half cone angle.

$$
\frac{\beta}{\alpha}=\exp (-j k l) \times \frac{1+j \frac{60}{Z_{0}} \sum_{n=1}^{\infty} \frac{2 n+1}{n(n+1)} P_{n}^{2}\left(\cos \theta_{0}\right) \zeta_{n}(k l)}{-1+j \frac{60}{Z_{0}} \sum_{n=1}^{\infty} \frac{2 n+1}{n(n+1)} P_{n}^{2}\left(\cos \theta_{0}\right) \zeta_{n}(k l)}
$$

$k=2 \pi / \lambda, \lambda$ is wavelength; $P_{n}\left(\cos \theta_{0}\right)$ is n-th-order Legendre polynomial; $\zeta_{n}(k l)$ is a helper function,

$$
\zeta_{n}(k l)=\frac{h_{n}^{(2)}(k l)}{h_{n-1}^{(2)}(k l)-\frac{n}{k l} h_{n}^{(2)}(k l)}
$$

$h_{n}^{(2)}(k l)$ is the second order Hankel function[6,7].

\section{The Construction and Design}

In this paper, the structure of the mono-cone antenna is shown in figure 2 . It used $50 \Omega$ coaxial feed, and the physical size is $\phi 140 \mathrm{~mm} \times 83 \mathrm{~mm}$. The distance from the conical radiator to the floor is $0.4 \mathrm{~mm}$. The diameter of the floor is $140 \mathrm{~mm}$ and the height is $20 \mathrm{~mm}$. As a antenna used for reverberation chamber, the antenna will be installed on reverberation chamber wall. The ground plane uses the bending design in order to facilitate the installation of the antenna and the connection of feeding coaxial line, at the same time, it can reduce the size as well. In order to reduce the weight and make it easier to take along and install, meanwhile we can guarantee the roundness of H-plane pattern by opening with a stepped hole in the cone. Because the antenna will be installed in the side wall and the top of reverberation chamber, we processed a ring made of Teflon which used to connect the cone and the floor to ensure the stability of antenna installation. It's thickness is $5 \mathrm{~mm}$ and the height is $61 \mathrm{~mm}$. This will not influence the measuring accuracy of the reverberation chamber and destroy the antenna performance.

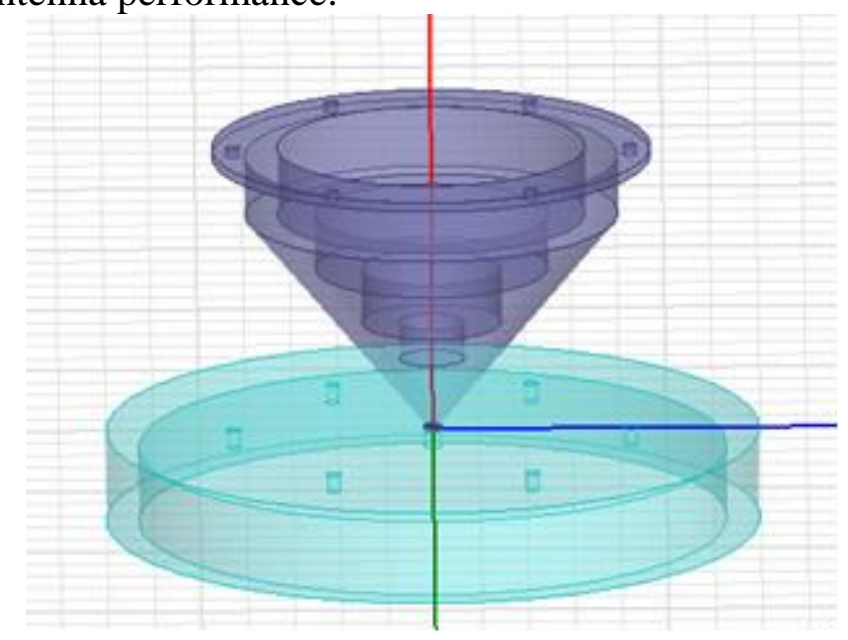

Fig.2 the simulation model of the antenna

\section{Simulated Result}

The proposed antenna is analyzed using the commercial software HFSS (v15). Set the radius of the floor, the bottom radius, the height of the cone, and the distance between cone and ground plate as optimization variables. Setting the optimization goal is the voltage standing wave ratio less than 2 . After parameters optimization, we get the main dimensions. 
After simulation, voltage standing wave ratio in the working frequency band will stay around 2 when the distance between cone and ground plate is $0.4 \mathrm{~mm}$. So fixed this variable, continue to optimize the size of the cone, we got the final size.

The simulated VSWR response are shown in Fig.3:

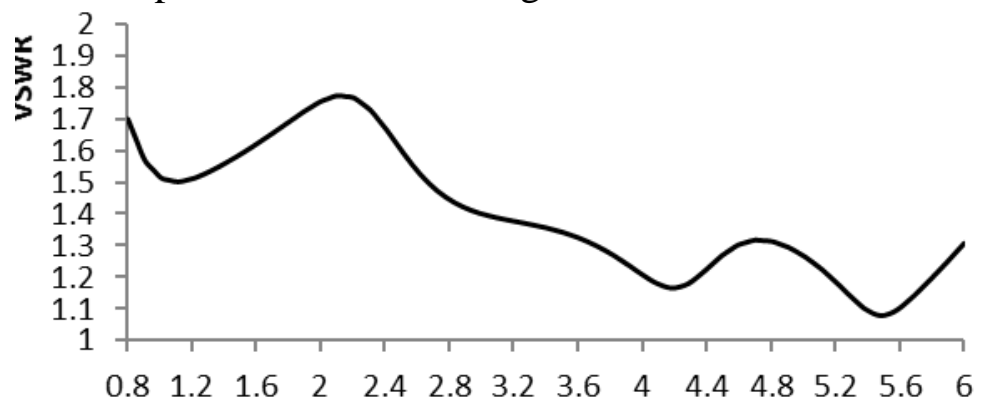

Fig.3 Simulated VSWR response

The simulation result shows that the antenna voltage standing wave ratio within $0.8-6 \mathrm{GHz}$ is less than 2, and the minimum value is 1.05 .

And the simulation results show that the radiation pattern are omnidirectional across the wideband. Fig. 4 shows the radiation patterns at $2 \mathrm{GHz}, 4 \mathrm{GHz}$, and $6 \mathrm{GHz}$, respectively, which exhibit the pattern of a typical monopole antenna.
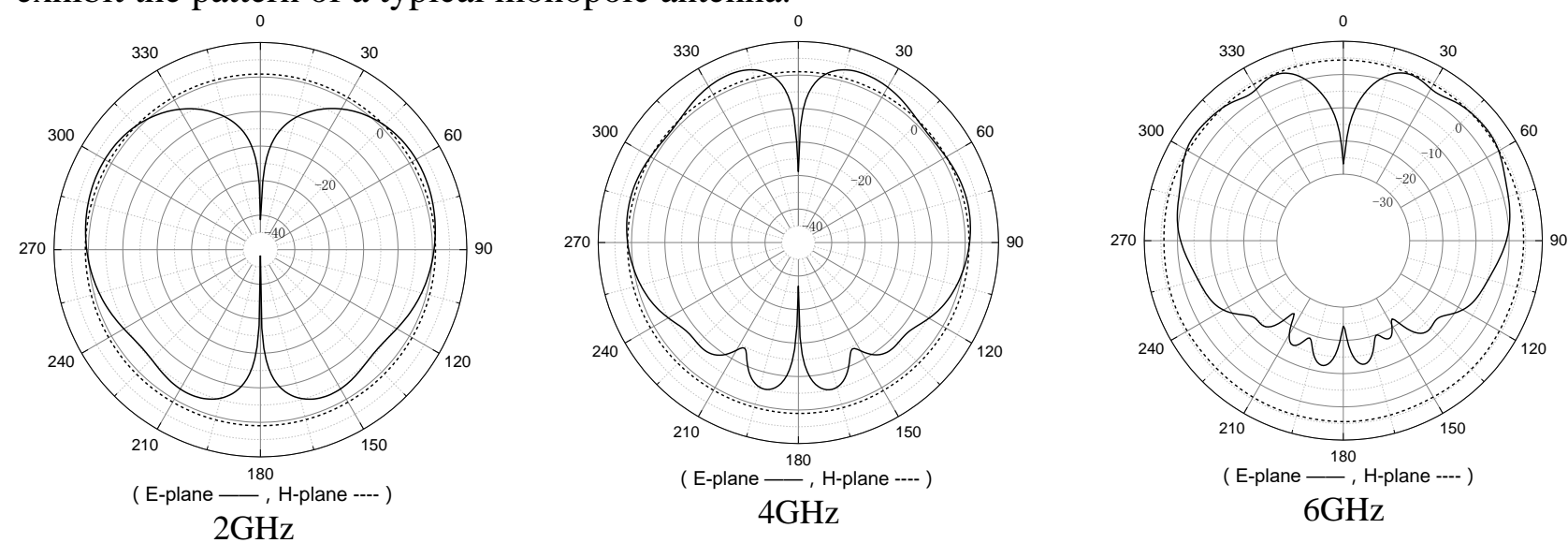

Fig.4 The radiation patterns at $2 \mathrm{GHz}, 4 \mathrm{GHz}$, and $6 \mathrm{GHz}$

As shown in Fig.4, the H-plane pattern has fine out-of-roundness which less than $1 \mathrm{~dB}$. It is consistent with the performance of the mono-cone antennas; The E-plane pattern is similar to an apple, and the gain is greater than $1 \mathrm{dBi}$ in all band.

\section{Conclusion}

In this paper, an ultra-wideband omnidirectional mono-cone antenna used for reverberation chamber has been proposed. The antenna is analyzed using the commercial software HFSS (v15), and the configuration and simulation results were provided. The simulation results show that the antenna has excellent impedance characteristics and omnidirectional radiation characteristics, and it meets to the performance requirements of the antenna used for reverberation chamber. Fig.5 shows the fabricated antenna. Fig.6 shows the measured value of VSWR within $0.8-6 \mathrm{GHz}$ is less than 2, this result is in accord with the simulation. The designed antenna can be used as a transmitting antenna, at the same time, it also can be used as a receiving antenna because of its small size and the omnidirectional radiation. The size of the antenna is reduced enormously. It is convenient to take along and install, and it has well practical values. 


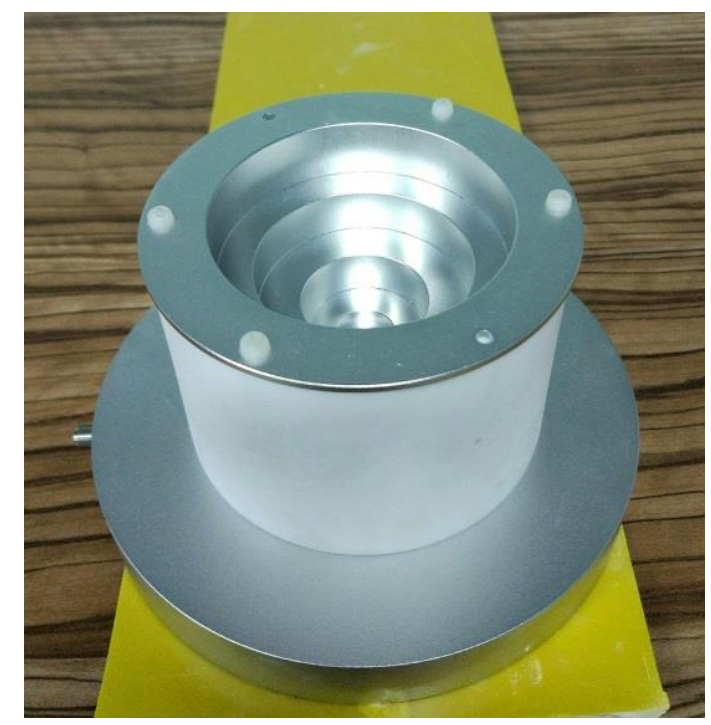

Fig.5 the fabricated antenna

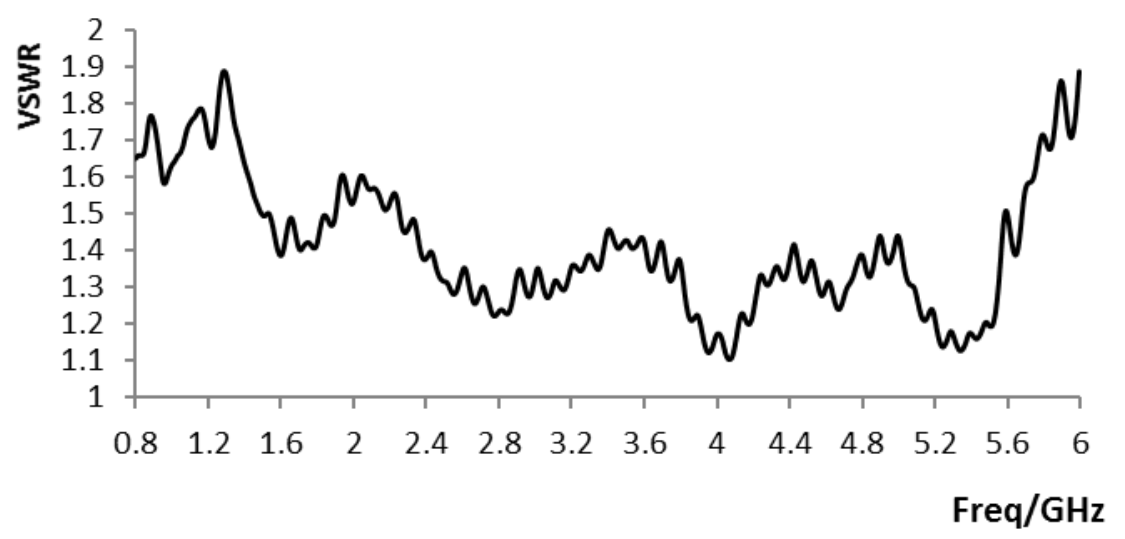

Fig.6 the measured value of VSWR

\section{References}

[1] ZURCHER, Antonio A. Moreira, A Novel Low-Profile Vertically-Polarized UWB Antennafor WBAN, IEEE Transactions on Antennas And Propagation, April (2014) Vol.62, No 4.

[2] WANG Hao, LU Long-long. 2.55-17 GHZ antenna miniaturization cone [J]. Modern Electronics Technique, (2012), Vol.35 No.11, in Chinese.

[3] ALIPOUR A, Hassani H R. A novel omni-directional UWB monopole antenna [J]. IEEE Transactions on Antennas and Propagation, (2008), 56(12): 3854-3857.

[4] YANG Hui-chun, GAO You-gang, Design of Broadband anti-interference directional single cone antenna $[\mathrm{J}]$. Journal of Beijing university of posts and telecommunications, (2011), Vol.34 No.6, in Chinese.

[5] HAO Mingshen. V-Conical Antenna [J]. IEEE Transactions on Antennas and Propagation, (1988),36(11).

[6] R. Bourtoutian, C. Delaveaud, Low proble UWB shorted dipole antenna, in Proc. IEEE Int.Symp.Antennas andPropag. Soc., (2007), pp. 57295732.

[7] RUAN Chengli, A Universal Model for Biconical Antennas. China Journal of Radio Science, (2001),16(1). 